\title{
The biological treatment of laboratory SBR model with biofilm
}

\author{
Tran Ha Quan ${ }^{1, *}$, Elena Gogina ${ }^{1}$ and Tran Van Quang ${ }^{2}$ \\ ${ }^{1}$ Moscow State University of Civil Engineering, Yaroslavskoe shosse, 26, Moscow, 129337, Russia \\ ${ }^{2}$ Enviromet Protect Research Centre, Danang University of Technology, Danang, Vietnam
}

\begin{abstract}
All around the world, activated sludge is the classical and traditional biological wastewater treatment for municipal and industrial wastewater. With the development of social and technology, the concentration of pollutants has been increased, so the performance of the old wastewater treatment plants not guaranteed. Therefore, upgrade and reconstruction wastewater treatment system becomes the main task of protection environment, especially in the developing countries. Application biofilms in process biological wastewater treatment is one of technology method and it has many advantages. In the Sequencing Batch Reactor, the Mutag BioChip $25^{\mathrm{TM}}$ provides to the bacteria an optimal habitat at the surface area, increasing rate of Utilization of Substrates $20-30 \%$ and efficiency of organic matter removal from $10-15 \%$.
\end{abstract}

\section{Introduce}

Biofilm is a well-organized, cooperating community of microorganisms, where bacteria attached and growth in the surface area. Difference from suspended cells, the biofilm associated cell reduced growth rate, up and down regulation of gene and generation of extracellular polymeric matrix [1]. Therefore, biofilms and their carrier media dominated in the technology of wastewater treatment for several decades, from natural material like rock, slag or redwood to artificial materials by plastic or polymer.

In the biological wastewater treatment, 2 main applications of biofilm is trickling filter and upgrade for process activated sludge, when they increase the performance of removal pollutants in wastewater [2]. This article is going to evaluate the application of carrier media Biochip 25 in Sequence Batch Reactor (SBR) for increasing the efficiency of pollutants removal in the biological treatment.

The Mutag BioChip 25 $5^{\mathrm{TM}}$ carrier has a diameter of approx. $25 \mathrm{~mm}$, a thickness of approx. $1.1 \mathrm{~mm}$ and a large number of closely spaced, open pores in the surface for immobilization of microorganisms. So the active surface area of them more than 4000 $\mathrm{m}^{2} / \mathrm{m}^{3}$ with open pores and channels provides the bacteria an optimal habitat at the surface area size mentioned above which accounts for a manifold of the surface area size provided by "conventional" biofilm carriers [3].

* Corresponding author: haquan.891300@gmail.com 


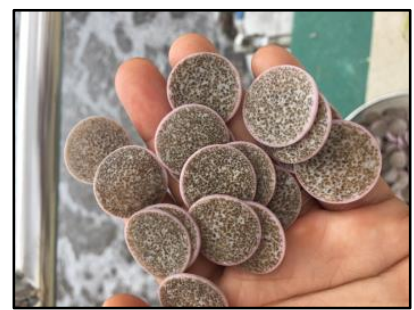

The new Mutag Biochip 25

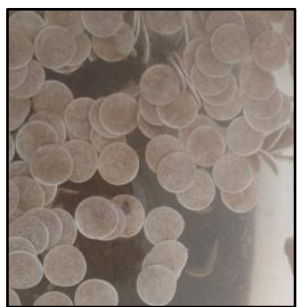

Biochip in the reactor

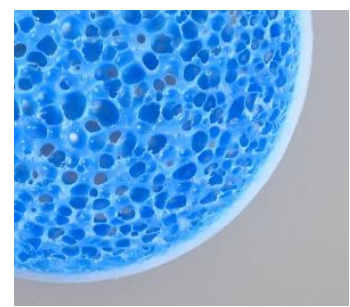

Pore system

Fig. 1. Carrier media Biochip 25

Therefore, the applications of Biochip 25 in the aerobic process of SBR has some advantages: At first, the reactor operates by phase in the fixed periods, so the situations of the media does not depend on the hydraulic flow of wastewater. Secondly, the clarifier and return pumps is not required in SBR and the mixed liquor with Biochip always keeps inside the reactor. However, the media has destiny of $0.95 \mathrm{~kg} / \mathrm{l}$, suspends in the reactor and it is appropriate for Fill and Mixing phase of reactor [4,5].

Table 1. Operation system of SBR

\begin{tabular}{|c|c|c|c|c|c|}
\hline Phase & 1 Fill & 2 React & 3 Settle & 4 Draw & 5 Idle \\
\hline Operation & 7 & 7 & & $\Gamma$ & $\Gamma$ \\
\hline & Mixer and Air & Mixed or Aerated & & Effluence & Waste sludge \\
\hline Cycle & $25 \%$ & $35 \%$ & $20 \%$ & $15 \%$ & $5 \%$ \\
\hline Volume & 25 to $100 \%$ & $100 \%$ & $100 \%$ & 100 to $35 \%$ & 35 to $25 \%$ \\
\hline
\end{tabular}

The combining experiment of the media carrier Biochip 25 with SBR reactor has been performed at laboratory Biological wastewater treatment, National Research Moscow University of Civil Engineering for calculate the optimal ratio of media per activated sludge and the performance of pollutants removal in the SBR model.

\section{Materials and methods}

The purpose of experiment is determined the optimal ratio of media per activated sludge and the efficiency of SBR with 2 main objectives: The Mutag Biochip 25 and the SBR model in laboratory. Therefore, the experiment process has been divided into 2 steps and shows on the Figure 2. 


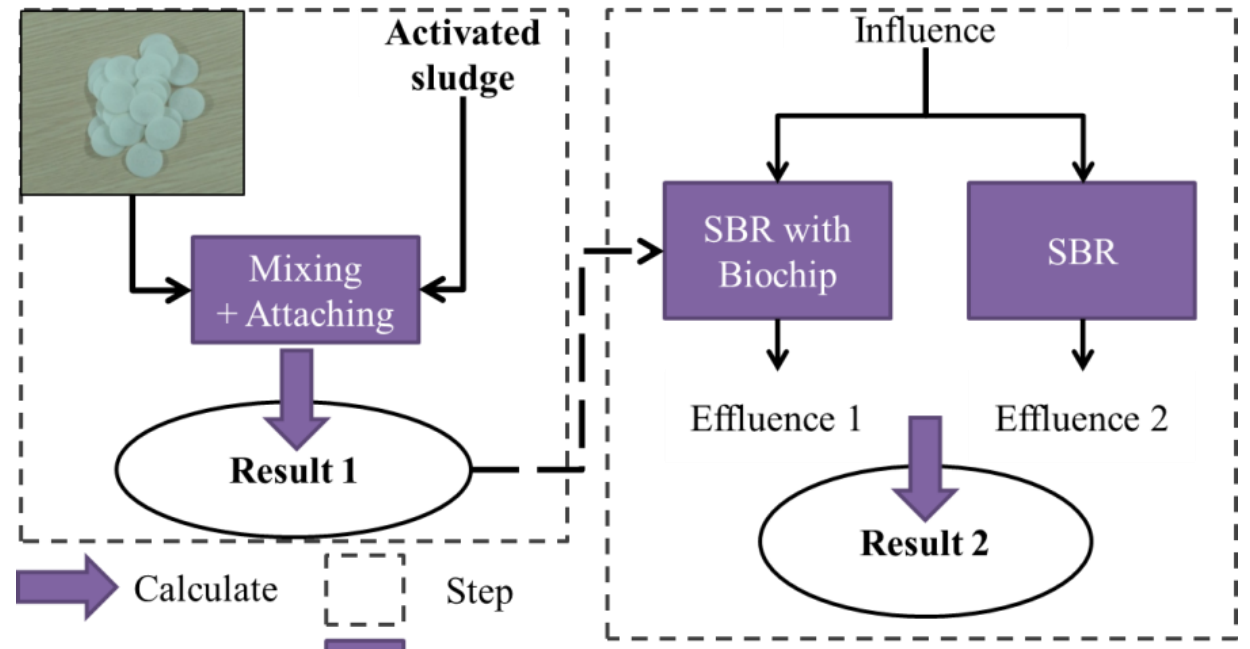

\section{$\longrightarrow$ Application $\quad$ Aerobic}

Fig. 2. 2 Steps of experiment

The first step of experiment is determined the attached ability of activated sludge into the Biochip's surface with ratio of media increased from $5 \% ; 10 \% ; 25 \% ; 35 \% ; 50 \%$ after $72 \mathrm{~h}$. Filling $50 \mathrm{ml}$ peptone solution to 6 bottles (from $0-5$ ) and Biochip with different amount $(0,1 ; 0,2 ; 0,5 ; 0,7 ; 1$ litre) to bottle No. $1-5$ and mix them. After that, pouring 2 litres activated sludge to every bottles, turn on the compressor (Figure 3 ) and analysis the mass' parameters after $8 ; 24 ; 28 ; 32 ; 48 ; 56 ; 72 \mathrm{~h}$.

Fill 2 liters activated sludge (each bottles) $-\mathrm{M}_{0.0}$

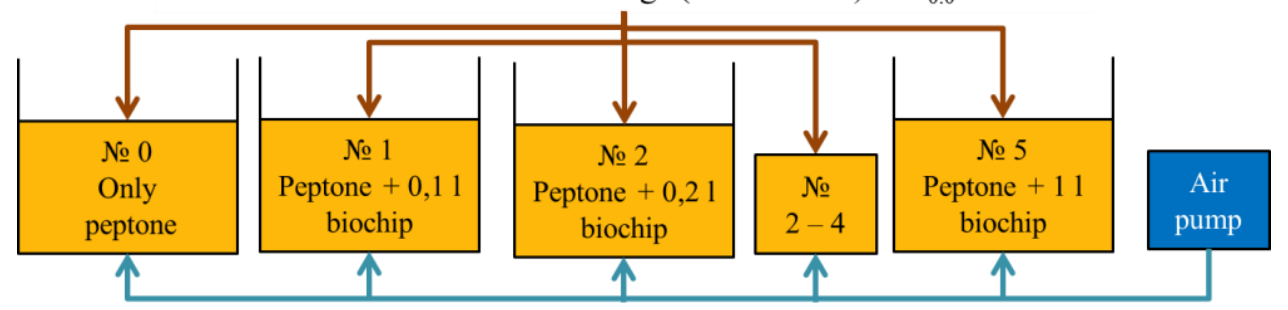

Fig. 3. Experimental diagram of 1 st step experiment

Under the same beginning conditions, with the mass of sludge in the bottle $\mathrm{X}$ ( $\mathrm{X}=1-$ 5 ) is equal to blank bottle (bottle 0) after T hours (1) and the sum sludge in the bottle X comprises of suspended sludge and attached sludge in the surface of Biochip (2).

$$
\left\{\begin{array}{c}
m_{0 . T}=m_{X . T}(1) \\
m_{X . T}=m_{p X . T}+m_{b X . T}(2)
\end{array}\right.
$$

With

Where:

$$
\begin{gathered}
m_{p X . T}=M_{p X . T} * V_{p} \\
m_{b X . T}=M_{b X . T} * V_{b X} \\
m_{0 . T}=M_{0 . T} * V_{p}
\end{gathered}
$$

$m_{X . T}$ and $M_{X . T}$ - mass and concentration of sludge in bottle X after T hours;

$m_{p X . T}$ and $M_{p X . T}$ - mass and concentration of suspended sludge in bottle X after T hours;

$m_{b X . T}$ and $M_{b X . T}$ - mass and concentration of attached sludge in bottle X after T hours; 
$V_{p}$ and $V_{b X}-$ volume of bottle and Biochip 25 in bottle $\mathrm{X}$

After determined the optimal ratio of Biochip per Volume Activated Sludge, operating parallel 2 SBR models, with 1 reactors using biofilm (Figure 4). Analysis the quality of influence and effluence of the model, including concentration $\mathrm{BOD}_{5}, \mathrm{COD}, \mathrm{N}-$ $\mathrm{NH}_{4}, \mathrm{~N}-\mathrm{NO}_{3}$ to comparing and evaluating the removal efficiency of media carrier Biochip.
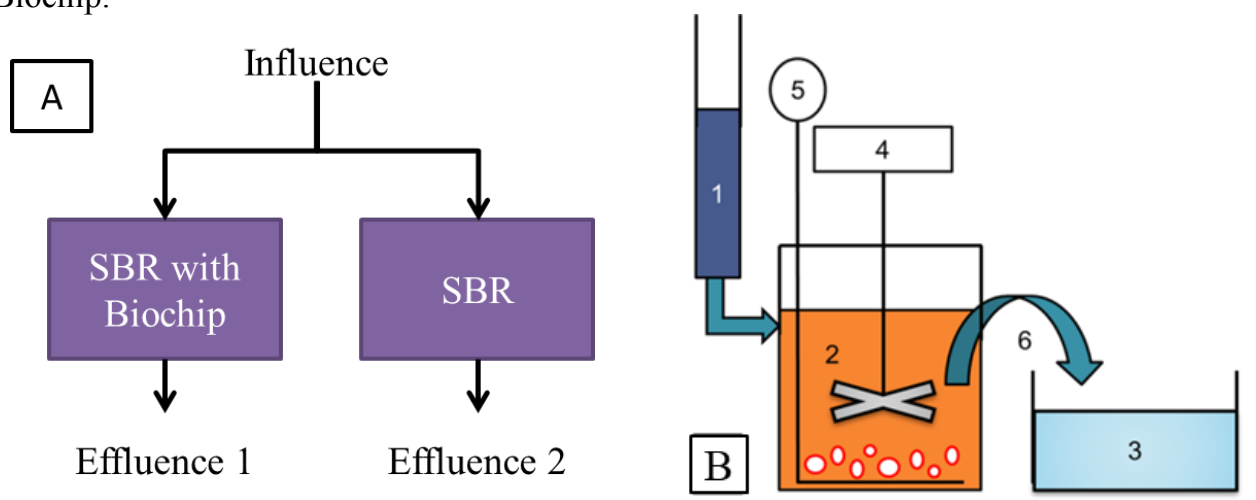

Fig. 4. The $2^{\text {nd }}$ step of experiment. A - SBR model and B - Devices each reactor: 1 Influence; 2 SBR (x2); 3 Effluence; 4 Mixer; 5 Compressor; 6 Decanter

From the results of analysis, determination the rate of utilization of soluble substrate and the specific biomass growth rate in the SBR with and without Biochip 25. The substrate utilization rate in biological systems can be modelled with Monod expression and because their mass is decreasing with time due to substrate utilization, a negative value is shown on $[2,8]$ :

Where

$$
\begin{gathered}
r_{s u}=-\frac{k S X}{K_{S}+S} \\
\mu=-Y \frac{k S}{K_{s}+S}-k_{d}
\end{gathered}
$$

$r_{s u}$ - rate of substrate concentration change due to utilization, $\mathrm{g} / \mathrm{m}^{3 *} \mathrm{~d}$

$k$ - maximum specific substrate utilization rate, $g$ substrate/g microorganisms*d

$S$ - growth-limiting substrate concentration in solution, $\mathrm{g} / \mathrm{m}^{3}$

$X$ - biomass concentration, $\mathrm{g} / \mathrm{m}^{3}$

$K_{S}$ - half-velocity constant, $\mathrm{g} / \mathrm{m}^{3}$

$Y$ - true yield coefficient, $\mathrm{g}$ VSS/g bsCOD

$k_{d}$ - endogenous decay coefficient, g VSS/g VSS*d

$\mu$ - specific bacterial growth rate, $\mathrm{g}$ VSS/g VSS*d

\section{Results and discussion}

\subsection{Result 1: Attached ability of activated sludge into the surface of Biochip}

The graphic in figure 5 shown that: the mass of activated sludge stabilizes after $36 \mathrm{~h}$ and reach the maximum value in the bottle 3 , when the ratio between Biochip per sludge is $25 \%$. The maximum concentration of activated sludge in total volume, including suspended in bottle and attached in the surface of media is $2.5 \mathrm{~g} / \mathrm{l}$ with ratio from $10-25 \%$. 

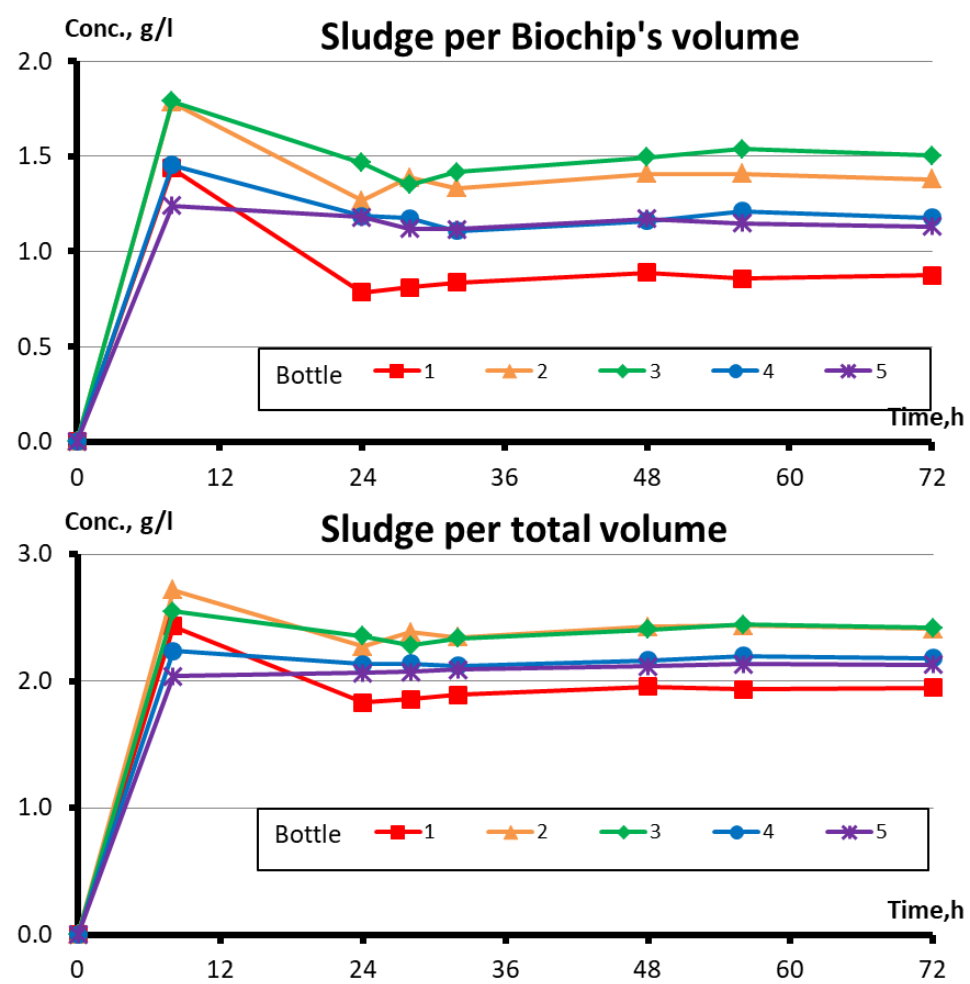

Fig. 5. Graph between mass of sludge and aeration time

\subsection{Result 2: compare the efficiency of 2 SBR reactor with one of them using the Biochip 25}

The curves of each graphic on Figure 6 show that: Biochip increases the efficiency of process removal organic matter from $10 \%$ to $15 \%$. In the process nitrification and removal ammonia in the influence, they increased 5\% and the maximum concentration of nitrate, which created by the biological treatment of effluence is $25 \mathrm{mg} / \mathrm{l}$.
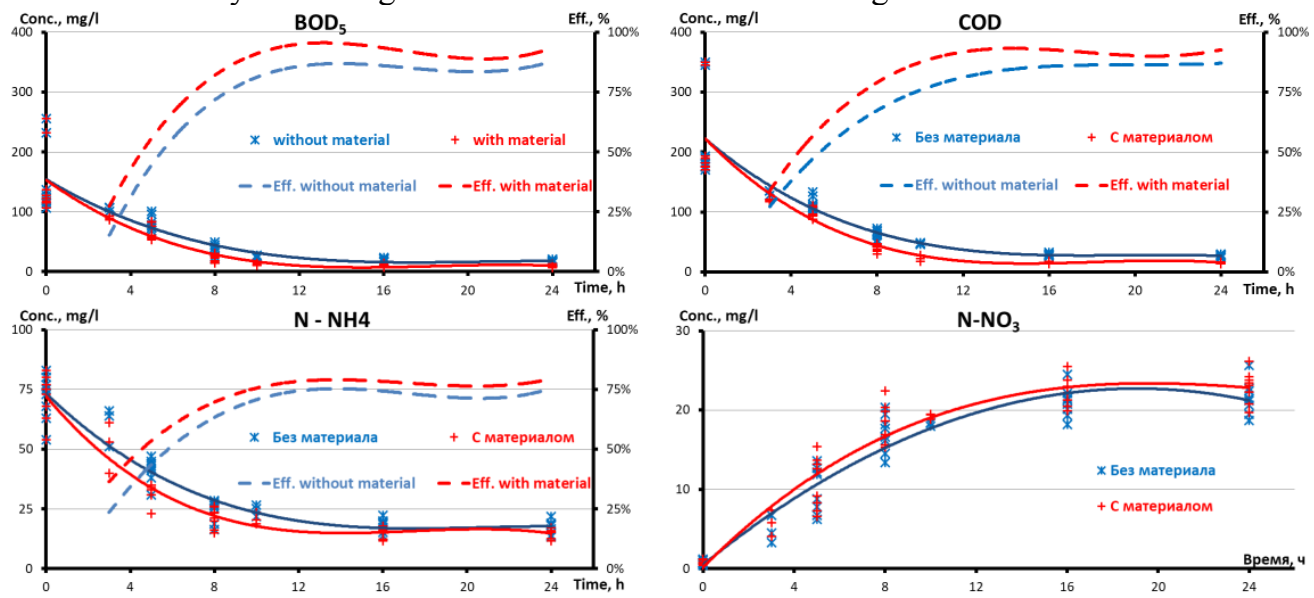

Fig. 6. Graph between mass of sludge and aeration time 
The utilization rate of substrate and the specific biomass growth rate have been showed in the Figure 7. With applications the media carrier Biochip, the rate of utilization of substrate increases $20-30 \%$, and it makes the increasing of specific biomass growth rate in the low period of BOD concentration. For this reason, the BOD and COD concentration of effluence stabilizes faster and the process removal organic matter with Biochip is better.
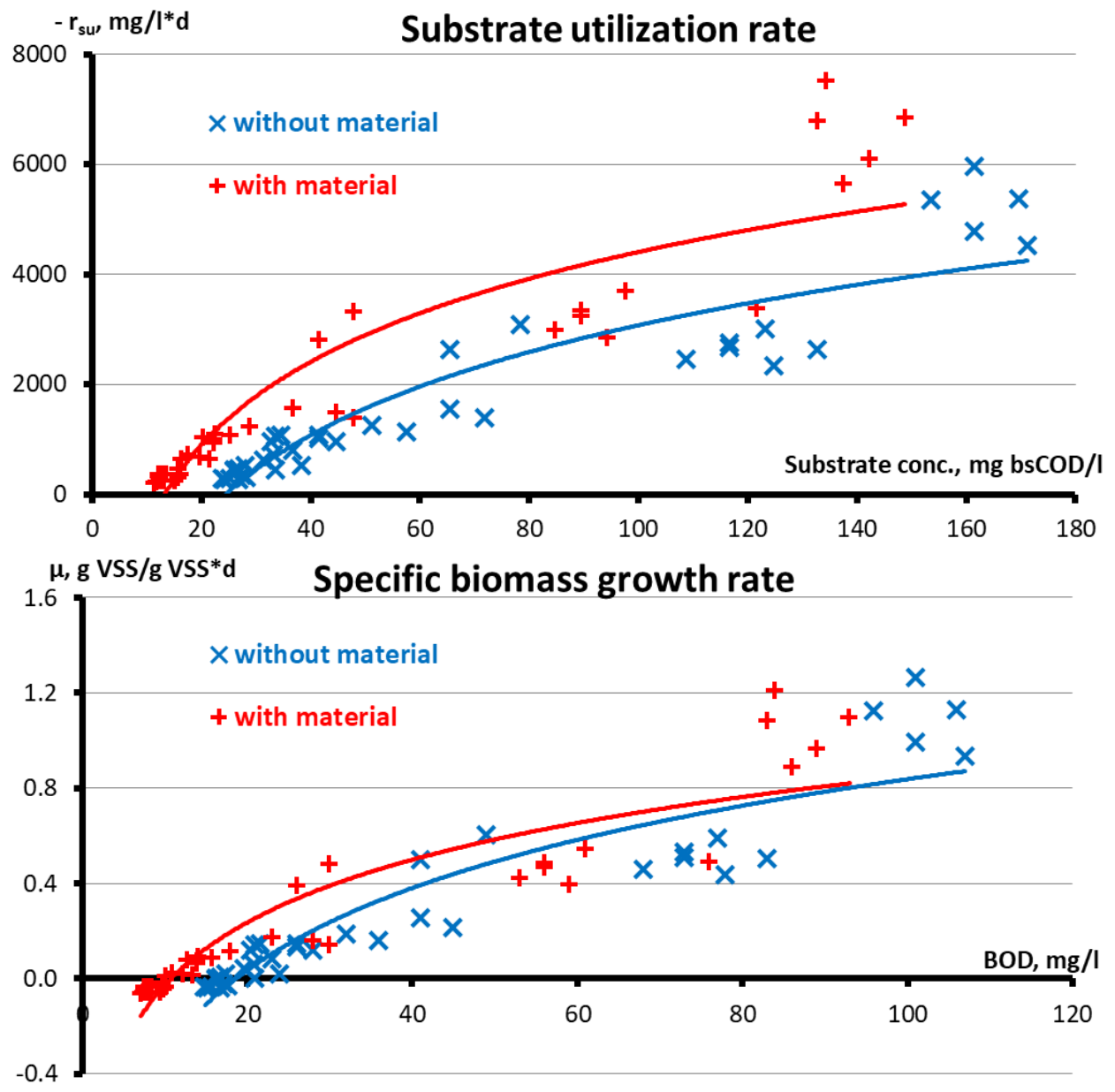

Fig. 7. Graph between the rate of biomass and organic matters in 2 SBR reactors

\section{Suggestions}

The applications of biofilms or plastic media carrier in the aerobic construction like aerotank, SBR,... is the technology method for increasing the efficiency of process biological wastewater treatment. It is also a good and inexpensive way to upgrade the wastewater treatment plan when the concentration of wastewater rising in the near future.

On the other hand, the nitrification process has a little change when using the Biochip 25. Therefore, it is necessary to research other operation modes to improve the ammonia removal, even so setting and operating a full - scale model to evaluate exactly the performance of them in the biological wastewater treatment process. 


\section{References}

1. C. R. Kokare, S. Chakraborty, A. N. Khopade, K. R. Mahadik. Biofilm: Importance and applications. Indian Journal of Biotechnology. Vol 8. 159 - 168 (2009)

2. Metcalf \& Eddy, Inc. 6. Wastewater engineering treatment and reuse (Fourth Edition)// The McGraw Hill Companies. Chapter 7. (2003)

3. Multi Umwelttechnologie AG. Instructions and recomendations for the operation of Mutag BioChip 25 ${ }^{\mathrm{TM}}$ carrier media

4. Tran Ha Quan, E. S. Gogina, Nguyen Xuan Quyet. The advantages of technology SBR in wastewater treatment. Collected, Conference Building - Forming a Living Environment. MGSU 1093 - 1096 (2017)

5. United States Environmental Protection Agency EPA/625/8-86/011. Summary report Sequencing Batch Reactor. (1986)

6. American Public Health Association. Standard Methods for the Examination of Water and Wastewater 20th Edition (1998)

7. Council of Economic Assistance. Standard methods for water quality. (1987)

8. S. V. Yakolev, T. A. Karukhina. Biological process in wastewater treatment. 136 (1980) 